\title{
Heavy Metal Leaching in Foods Cooked with Stainless-steel Pots and Locally made Alloy Pots
}

Gloria N. Elemo, Abayomi S. Yusuf, Toheeb A. Aderoju, and Olajumoke K. Adebayo

\section{ABSTRACT}

Heavy metals are widely distributed across the earth crust but are present in very low concentrations in the human body. An increased concentration (above safe levels) in the human body can lead to several deleterious health issues such as chronic degenerative changes to organs, teratogenic and carcinogenic effects, lipid peroxidation and DNA damage. An increased concentration can be as a result of ingestion of foods contaminated by heavy metals. The aim of this work is to determine the safeness of stainless-steel pots and alloy pots from heavy metal leaching while also comparing leached heavy metals in food samples cooked with the two commonly used pots in Nigeria. Five food samples were used in this research and were prepared using local procedures. Atomic absorption spectrometer (AAS) was used to determine the concentration of manganese $(\mathrm{Mn})$, copper $(\mathrm{Cu})$, lead $(\mathrm{Pb})$, zinc $(\mathrm{Zn})$, chromium $(\mathrm{Cr})$ and cadmium $(\mathrm{Cd})$ in the food samples. Generally, our results suggest that both pots are averagely safe but continuous usage of these pots could pose some health challenge especially for the stainlesssteel pot that consistently leached higher concentration of the analyzed heavy metals. These metals, though in low concentrations, have the potential to bioaccumulate in the body without severe side-effects. High bioavailability and subsequent accumulation of these metals in the body can negatively affect the human health.

Keywords: Alloy pots, Bioaccumulate, Bioavailability, Stainless-steel pots.
Published Online: October 13, 2021

ISSN: $2684-4478$

DOI :10.24018/ejchem.2021.2.4.76

\section{G. N. Elemo*}

Department of Chemical Sciences, Biochemistry, Ajayi Crowther University, Oyo, Nigeria.

(e-mail: gn.elemo@acu.edu.ng)

A. S. Yusuf

Department of Chemical Sciences, Biochemistry, Ajayi Crowther University, Oyo, Nigeria.

(e-mail: ys.abayomi@gmail.com)

T. A. Aderoju

Department of Chemical Sciences, Biochemistry, Ajayi Crowther University, Oyo, Nigeria.

(e-mail: hardehrojuh ${ }^{@}$ gmail.com)

O. K. Adebayo

Department of Chemical Sciences, Biochemistry, Ajayi Crowther University, Oyo, Nigeria.

(e-mail: olajumokeadebayo23@gmail.com)

*Corresponding Author

\section{INTRODUCTION}

About 600 million (almost 1 in 10) people in the world fall ill after eating contaminated food and as a result, 420,000 die yearly [1]. Contamination by heavy metals contributes to these recorded deaths.

Heavy metals are widely distributed across the earth crust but are present in very low concentrations in the human body. An increased concentration (above safe levels) in humans can cause several deleterious health issues such as chronic degenerative changes to several organs (most importantly the liver, kidney and brain) [2], teratogenic and carcinogenic effects [3], lipid peroxidation and DNA damage [4]. There deleterious effects are majorly due to their collective action; since exposure to one specific heavy metal is usually accompanied by exposure to one or more of the others [5], which accumulates in the body over time.

Exposure to heavy metals can come through occupational exposure, environmental contamination, and/or accumulation in food [5]. In Nigeria today, one of the least investigated mode of heavy metals poisoning is through the leaching of metallic cookware, which is surprising because, the few studies that have done the investigation, have confirmed heavy metal leaching from household cookware into foods and liquids [6], [7]. Ogidi et al. (2017) reported heavy metal leaching from different pots into beans and tomato sauce samples in Ibadan, Nigeria. The research which was carried out in Iddo Local Government of Ibadan suggested that different foods have different potential of accumulating trace metals depending on the pot used, the type of food and the process applied.

Several staple foods in Nigeria require different food processes and the choice of pots used is usually based on what is available/predominant in the market or area. While alloy pots are mostly used in the rural areas and suburban areas, stainless-steel pots are mostly used in the urban cities of Nigeria.

The aim of this work is to determine the safeness of the two pots from leaching while also comparing leached heavy metals in food samples cooked with the two commonly used pots in Nigeria.

\section{MATERIALS AND METHOdS}

Materials used included locally-made alloy pots, standard pots, weighing balance, crucible, desiccator, tongs, spatula, pestle and mortar, vacuum oven and atomic absorption spectrometer (AAS). Food samples used were rice, beans, wheat middling flour (semo), yam flour (amala), and grinded 
corn (tuwo masara), Reagents used include nitric acid $\left(\mathrm{HNO}_{3}\right)$, perchloric acids $\left(\mathrm{HCLO}_{4}\right)$ and deionized water.

\section{A. Preparation of Food Sample}

Food samples were cooked (using local procedures) separately in each of the two pots. The procedure was repeated three times for each of the food samples using the two pots. Cooked foods were then allowed to cool and then weighed using a crucible of known mass. The cooked foods were subsequently oven-dried using a vacuum oven. The food samples were oven-dried at $65^{\circ} \mathrm{C}$ at less than $100 \mathrm{~mm} \mathrm{Hg}$ for 5 hours and weighed. Samples were subsequently weighed at 1 hour intervals until a dry mass was achieved.

\section{B. Digestion of Samples}

Samples were digested according to the method described by the Association of Official Analytical Chemists [8] with slight modifications.

$1 \mathrm{~g}$ of each sample was weighed accurately on an analytical balance and transferred to a washed and dried ceramic crucible. The sample was washed in a carbonite furnace of $1000{ }^{\circ} \mathrm{C}$. After washing, the sample was transferred into a desiccator. After cooling, $1 \mathrm{ml}$ concentrated Nitric acid was added to dissolve the sample. The solution was then transferred into $50 \mathrm{ml}$ volumetric flask and made up to mark.

The extracts were transferred quantitatively into preheated plastic sample bottles, tightly closed, and kept in a refrigerator (at $4{ }^{\circ} \mathrm{C}$ ) until ready for use.

\section{Determination of Heavy Metals}

Concentration of heavy metals $(\mathrm{Mn}, \mathrm{Cu}, \mathrm{Cd}, \mathrm{Zn}, \mathrm{Pb}$ and $\mathrm{Cr}$ ) in food samples were detected using Thermo SOLAAR Atomic Absorption Spectrometer. Analysis was done according to manufacturer's procedure.

\section{Statistical Analysis}

All statistical analysis was performed using Graph pad prism 5(statistical software). Results were first expressed as mean \pm standard errors of mean (SEM) with a $95 \%$ confidence interval for mean.

Comparisons were done using two-way ANOVA, while Bonferroni posttest was used to identify significant mean bars and extent of significance. Values of $\mathrm{P}<0.05$ were considered statistically significant.

\section{RESULTS AND DISCUSSION}

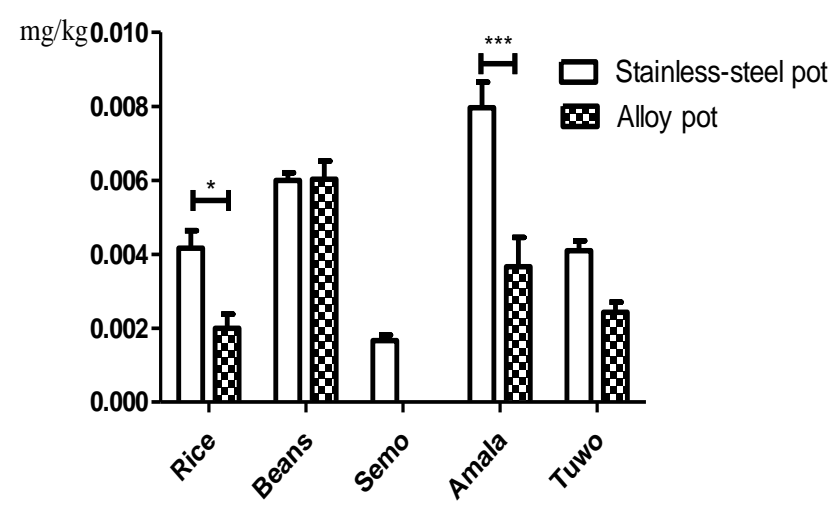

Fig. 1. Comparative concentration of manganese (Mn) leached into the food samples from each of the two pots. Mean bars having "*" and "***" shows significant difference at $P>0.05$ and $P>0.001$, respectively.
Manganese (Mn) is well known as a cofactor for a wide variety of important enzymes (such as pyruvate carboxylase and superoxide dismutase) that are involved in several metabolic pathways. However, overexposure (which could be through ingestion) can lead to neurodegenerative damage, liver and lung toxicity [9].

Generally, our result shows that food samples cooked with stainless-steel pots have higher concentrations of manganese leached into them; with the concentrations of Mn leached into rice and amala from stainless-steel pots been significantly higher than those cooked with alloy pots. However, the mean values (with the highest mean value of $0.008 \mathrm{mg} / \mathrm{kg}$ ) observed show that both pots are safe for cooking since the mean values are far from the minimum daily requirement $(0.74 \mathrm{mg} /$ day $)$ of manganese in food as reported by Friedman et al. [10].

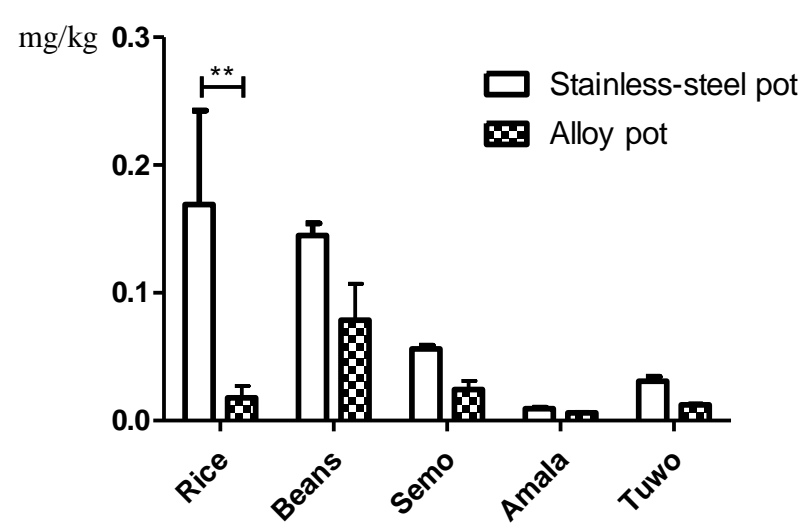

Fig. 2. Comparative concentration of copper $(\mathrm{Cu})$ leached into the food samples from each of the two pots. Mean bars having "**" shows significant difference at $P>0.01$.

Copper $(\mathrm{Cu})$ is also another well-known mineral element required as a catalytic cofactor in numerous critical enzymatic reactions in metabolism [11] but with its own toxicity level also.

Our result also indicates that foods cooked with stainlesssteel pots had higher concentrations of copper leached into them as compared with those cooked with alloy pot; with the rice samples showing a significant difference. The mean concentration of copper $(0.17 \mathrm{mg} / \mathrm{kg})$ in the rice sample cooked with stainless-steel pot calls for concern as a recent study [12] reports a safe ingestion concentration of copper to be $0.4 \mathrm{mg} / \mathrm{kg}$. This is particularly troubling because rice is a highly and regularly consumed food among in the young population in Nigeria. This popular food is eaten by some everyday of the week (with very few days exempted in a month) which increases its bioavailability and accumulation in the body.

This category of people is highly susceptible to copper toxicity which have been reported to cause some gastrointestinal symptoms such as nausea and abdominal pain [13] in acute stages. Studies have also reported liver toxicity in cases of chronic toxicity of copper [14]. 


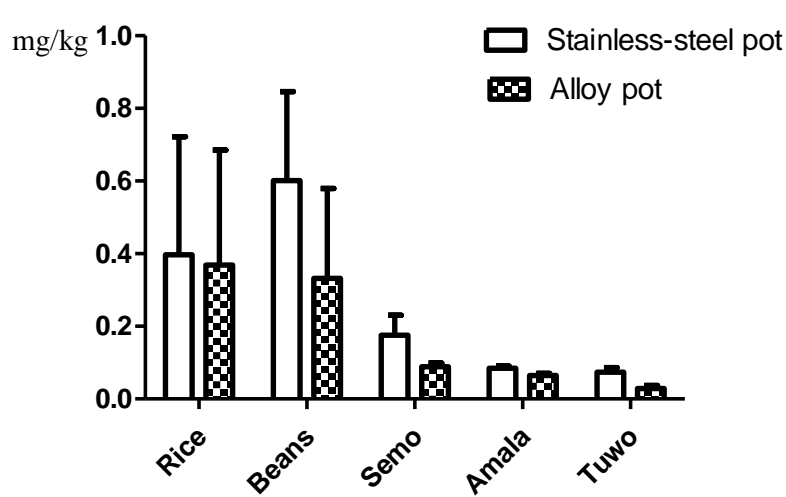

Fig. 3: Comparative concentration of zinc ( $\mathrm{Zn})$ leached into the food samples from each of the two pots.

This result shows no significant difference in the concentrations of the zinc leached into the food samples. The result also suggests that both pots may not directly cause or be involved in the toxic effects of zinc in the body as the estimated daily intake average of zinc is between 15-20 $\mathrm{mg}$ /day depending on age [15], [16] while the highest mean value in our result is $0.6 \mathrm{mg} / \mathrm{kg}$.

Zinc is an important cofactor involved in several biomolecular functions such as DNA and RNA metabolism and stabilization of large number of proteins [17]. Its presence, as shown in our result, is not bad since it is well below the estimated safe level.

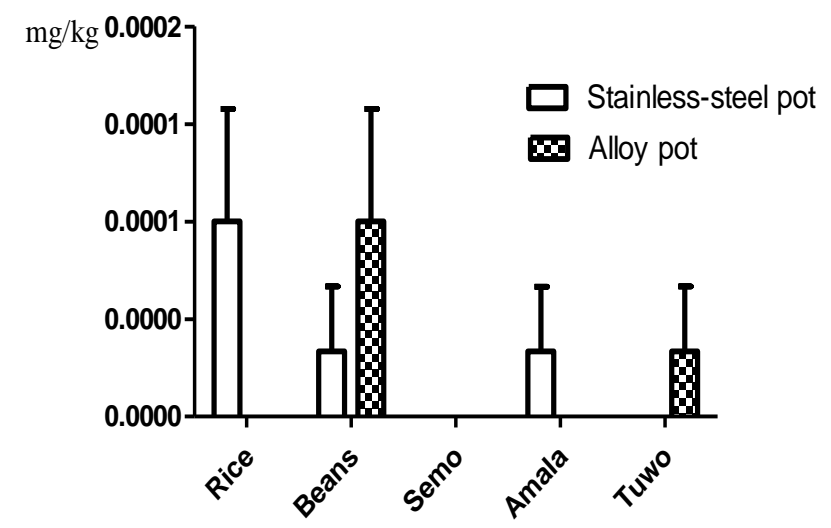

Fig. 4. Comparative concentration of lead $(\mathrm{Pb})$ leached into the food samples from each of the two pots.

This result shows no significant difference in the concentrations of lead leached into the food samples. The result also suggests how safe these pots are from lead poisoning with no lead detected in rice, semo and amala samples cooked with alloy pots as well as semo and tuwo samples cooked with stainless-steel pots. The highest mean concentration of the lead detected was $0.0001 \mathrm{mg} / \mathrm{kg}$ which is very low compared to the maximum expected daily intake of lead which is reported to be $0.13 \mathrm{mg} /$ day [6].

Lead is a very dangerous heavy metal poison that can accumulate in the body over time to cause neurological and behavioral, renal, cardiovascular dysfunction [6]. Thus, it is important that its levels are well monitored and are way below toxic levels in foods at all times.

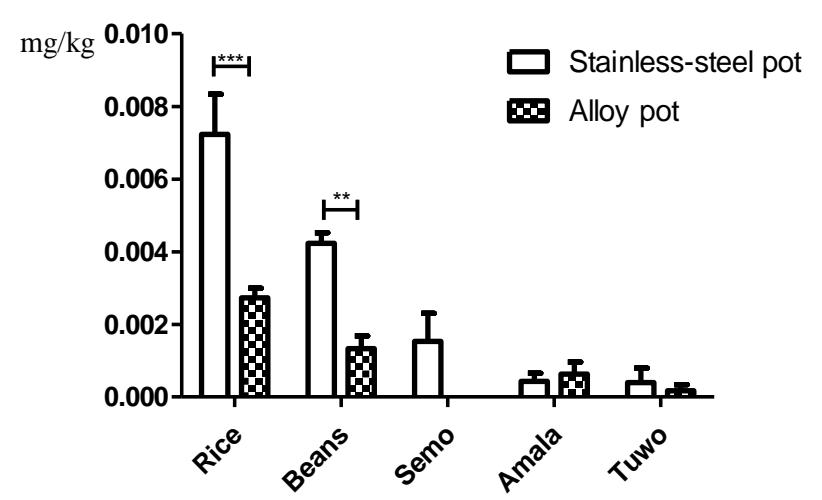

Fig. 5: Comparative concentration of chromium $(\mathrm{Cr})$ leached into the food samples from each of the two pots. Mean bars having "**” and "***" shows significant difference at $\mathrm{P}>0.01$ and $\mathrm{P}>0.001$ respectively.

Chromium is an important mineral in the human body that assists insulin function [18], diabetes mellitus, metabolic syndrome and polycystic ovarian syndrome [19]. However, its toxicity, which is usually associated with $\mathrm{Cr}-\mathrm{VI}$, could be equally bad as its accumulation can lead to cancer [20], [21]. The safe limit per day of Chromium has thus been reported to be $0.55 \mathrm{mg} /$ day [22].

Although, our result shows that rice and beans samples cooked with stainless-steel pots had significantly higher concentrations of chromium leached into them than those cooked with alloy pots but the mean concentrations $(0.007 \mathrm{mg} / \mathrm{kg}$ and $0.004 \mathrm{mg} / \mathrm{kg}$ respectively), these values however appear to be well below the safe limit of $0.55 \mathrm{mg}$ per day.

It is important to note that there was no cadmium detected in all the food samples analyzed for both pots.

Generally, our results suggest that both pots are averagely safe but continuous usage of these pots could pose some health challenge especially for the stainless-steel pot that consistently leached higher concentration of the analyzed heavy metals. These metals, though in low concentrations, have the potential to bioaccumulate in the body without severe side-effects. High bioavailability and subsequent accumulation of these metals in the body can negatively affect the human health.

\section{CONCLUSION}

In conclusion, our results indicate that both pots are safe from leaching of the heavy metals analyzed with the exception of copper whose bioavailability in the body could be increased above safe levels as a result of continuous eating of foods cooked with the stainless-steel pots.

\section{COMPETING INTERESTS}

Authors have declared that no competing interests exist.

\section{REFERENCES}

[1] World Health Organization. "Food safety 2020," Available: https://www.who.int/news-room/fact-sheets/detail/food-safety.

[2] D. Ibrahim, B. Froberg, A. Wolf, D. E. Rusyniak, "Heavy metal poisoning: clinical presentations and pathophysiology," Clinics in laboratory medicine, vol. 26, no. 1, pp. 67-97, 2006. 
[3] Cancer IAfRo, "IARC monographs on the evaluation of the carcinogenic risk of chemicals to humans," Cross index of synonyms and trade names in vols. 1 to 46.1989.

[4] M. Valko, H. Morris, M. Cronin, "Metals, toxicity and oxidative stress," Current medicinal chemistry, vol. 12, no. 10, pp. 1161-1208, 2005.

[5] E. M. Alissa, G. A. Ferns, "Heavy Metal Poisoning and Cardiovascular Disease," Journal of Toxicology, doi: 2011:870125, September, 2011.

[6] M. Ogidi, M. Sridhar, A. Coker, "A follow-up study health risk assessment of heavy metal leachability from household cookwares," $J$ Food Sci Toxicol, vol. 1, no. 1, pp. 3, 2017.

[7] O. A. Alabi, M. A. Unuigboje, D. O. Olagoke, Y. M. Adeoluwa, "Toxicity associated with long term use of aluminum cookware in mice: A systemic, genetic and reproductive perspective," Mutation Research/Genetic Toxicology and Environmental Mutagenesis, doi: 861:503296, 2021.

[8] AOAC, "Official methods of analysis," Aoac Washington, DC, 1990.

[9] J. Crossgrove, W. Zheng, "Manganese toxicity upon overexposure. NMR in Biomedicine," An International Journal Devoted to the Development and Application of Magnetic Resonance In Vivo, vol. 17, no. 8, pp. 544-553, 2004.

[10] B. Friedman, J. H. Freeland-Graves, C. W. Bales, F. Behmardi, R. L. Shorey-Kutschke, R. A. Willis, et al., "Manganese balance and clinical observations in young men fed a manganese-deficient diet," The Journal of nutrition, vol. 117, no. 1, pp. 133-143, 1987.

[11] B. R. Stern, "Essentiality and toxicity in copper health risk assessment: overview, update and regulatory considerations," Journal of Toxicology and Environmental Health, Part A, vol. 73, no. 2-3, pp. 114127, 2010.

[12] A. A. Taylor, J. S. Tsuji, M. R. Garry, M. E. McArdle, W. L. Goodfellow, W. J. Adams, et al., "Critical review of exposure and effects: Implications for setting regulatory health criteria for ingested copper," Environmental management, vol. 65, no. 1, pp. 131-159, 2020.

[13] M. Olivares, M. Araya, F. Pizarro, R. Uauy, "Nausea threshold in apparently healthy individuals who drink fluids containing graded concentrations of copper," Regulatory Toxicology and Pharmacology, vol. 33, no. 3, pp. 271-275, 2001.

[14] N. Nayak, A. Chitale, "Indian childhood cirrhosis (ICC) \& ICC-like diseases: the changing scenario of facts versus notions," The Indian Journal of Medical Research,vol. 137, no. 6, pp. 1029, 2013.

[15] FAO, WECoF, WHO, "Evaluation of certain food additives and contaminants," Forty-fourth report of the Joint FAO/WHO Expert Committee on Food Additives, 1995.

[16] FAO, WECoF, WHO, "Evaluation of certain food additives and contaminants," Thirty-third report of the Joint FAO/WHO Expert Committee on Food Additives, 1989.

[17] C. T. Chasapis, A. C. Loutsidou, C. A. Spiliopoulou, M. E. Stefanidou, "Zinc and human health: an update," Archives of toxicology, vol. 86, no. 4, pp. 521-534, 2012.

[18] E. J. O'Flaherty, B. D. Kerger, S. M. Hays, D. J. Paustenbach, “A physiologically based model for the ingestion of chromium (III) and chromium (VI) by humans," Toxicological Sciences, vol. 60, no. 2, pp. 196-213, 2001.

[19] J. T. Heimbach, R. A. Anderson, "Chromium: Recent Studies Regarding Nutritional Roles and Safety." Nutrition Today, 2005, Issue. 40, ch. 4.

[20] Cancer IAfRo, "Chromium, nickel and welding," IARC monographs on the evaluation of carcinogenic risks to humans, 1990, pp. 49.

[21] T. Stedeford, C-H. Hsu, Q. J. Zhao, M. L. Dourson, M. Banasik, "The application of non-default uncertainty factors in the US EPA's integrated risk information system (IRIS). Part I: UF L, UF S, and 'other uncertainty factors,', Journal of Environmental Science and Health Part C, vol. 25, no. 3, pp. 245-279, 2007.

[22] T. Berner, M. Murphy, R. Slesinski, "Determining the safety of chromium tripicolinate for addition to foods as a nutrient supplement," Food and chemical toxicology, vol. 42, no. 6, pp. 1029-1042, 2004. 